\title{
EVALUATION OF INTERNAL FIT, MARGINAL INTEGRITY AND FATIGUE RESISTANCE OF E-MAX CAD CROWNS ON TWO DIFFERENT PREPARATION DESIGNS FOR MAXILLARY ANTERIOR TEETH. AN INVITRO STUDY
}

\author{
Noha Adel Elkhodary* and Mostafa abo-Shahba ${ }^{* *}$
}

\begin{abstract}
Statement of the problem: Preservation of the cingulum in anterior teeth have been recommended however with recent ceramic restorations its contribution to internal adaptation and fatigue resistance needs further study.
\end{abstract}

Objective: The purpose of this in-vitro study was to evaluate the internal fit, marginal integrity and the fatigue resistance of E-max CAD crowns on two preparation designs for maxillary anterior teeth.

Material and methods: Twenty defect free human maxillary central incisors were prepared to receive E-max CAD ceramic crowns. 10 samples were prepared with parallel labiolingual wall (anatomic) group A and 10 samples were prepared with elimination of the cingulum (non-anatomic) group B. Scanning was done using powder free Identica hybrid scanner (Medit 02855] 23, Inchonro 22-gil, Seongbuk-gu, Seoul, Korea), designing was made by Exocad software version 2016 (Exocad Gmbh Julius-Reiber-Strabe 37, 64293 Darmstadt, Germany) then the restoration was milled by Roland DWX-510 milling machine (15363 barranca Parkway Irvine, California 92618) from E-max CAD blocks (LT) (Ivoclar Vivadent AG, 9494 Schaan, Princiability of Liechtenstein). Internal fit, marginal adaptation was measured before cementation using replica technique on prepared tooth using stereomicroscope. Duplication of the preparation was made in order to get epoxy resin dies for crown cementation, then restorations were cemented on the corresponding epoxy resin die and marginal adaptation was reevaluated under stereomicroscope. Specimens were then subjected to thermomechanical aging using four stations multimodal ROBOTA chewing simulator (Model ACH-09075DC-T, AD-TECH TECHNOLOGY CO., LTD., GERMANY) followed by fatigue resistance measurement using universal testing machine (Model 3345; Instron Industrial Products, Norwood, MA, USA).

Results: It was found that group $\boldsymbol{B}$ recorded statistically significant $(\mathrm{P}<0.05)$ higher marginal gap mean value $(29.7 \pm 3.97 \mu \mathrm{m})$ than group $\boldsymbol{A}(25.39 \pm 3.24 \mu \mathrm{m})$ as indicated by unpaired t-test

\footnotetext{
* Lecturer of Fixed Prosthodontics Department Faculty of Dentistry, Cairo University, Egypt.

** Lecturer of Fixed Prosthodontics Department Future University, Egypt.
} 
before cementation while after cementation it was found that group $\boldsymbol{B}$ recorded statistically nonsignificant $(\mathrm{P}>0.05)$ higher marginal gap mean value $(37.15 \pm 5.34 \mu \mathrm{m})$ than group $\boldsymbol{A}(34.2 \pm 4.84$ $\mu \mathrm{m})$. while for the internal adaptation it was found that group $\boldsymbol{A}$ recorded statistically significant higher internal gap mean value $(91.93 \pm 17.41 \mu \mathrm{m})$ than group $\boldsymbol{B}(57.97 \pm 14.08 \mu \mathrm{m})$. It was found that Group $\boldsymbol{B}$ recorded statistically non-significant higher fatigue resistance mean value $(1130.58 \pm 31.53 \mathrm{~N})$ than Group A $(1114.84 \pm 45.04 \mathrm{~N})$.

Conclusion: Different preparation designs affect the marginal adaptation of the restoration which was statistically significant only before cementation. The non-anatomic group (B) showed statistically significant lower internal gap than anatomic group (A). While there was no significant difference in the fatigue resistance of both groups after thermocyclic loading.

KEY WORDS: E-max CAD, Internal fit, Fatigue resistance, Marginal integrity, Preparation design.

\section{INTRODUCTION}

Nowadays restoration of maxillary anterior teeth have been challenging especially when the tooth has to be restored with full coverage restoration due to the need to fulfill the esthetic, mechanical and biological requirements.

In order to fulfill those biomechanical, esthetics and functional purposes we must preserve the sound tooth structure, marginal integrity, the periodontium, structural durability and to provide adequate resistance and retention form ${ }^{(1,2)}$.

Studies have shown that the preparation design greatly affect the resistance and retention form of a restoration ${ }^{(3)}$. Jorgenson in $1955^{(4)}$ stated that whenever the convergence angle of the preparation increases the less its ability to retain the restoration. Therefore in order to obtain a retentive restoration parallel walls are required; however studies showed that parallel walls increase the risk of undercuts and therefore affect the seating of the restoration. Resistance form is also affected by the taper of the preparation as increasing the taper of the preparation will decrease its resistance ${ }^{(5)}$.

Mostly in maxillary anterior teeth the direction of functional forces directed from the palatal towards the labial in a horizontal direction may tend to torque or rotate the restoration which may lead to its fracture or even dislodgement. So sufficient tooth structure must be removed specially at the functional area using ceramic restoration to give maximum bulk of restoration that can resist fracture of both restoration and tooth underneath. However although conservation is preferred but complete coverage ceramic restoration could be the better choice by most of the patients nowadays.

One of the most important aspect of the success of the restoration is the marginal integrity, as poor marginal fit can result in periodontal disease, recurrent caries, cement dissolution and finally failure of the restoration ${ }^{(6,7)}$. In a study made by McLean and Von Fraunhofer in $1971^{(8)}$ after evaluation of nearly 1000 metal ceramic crown they found a maximum discrepancy of 120 um for the restoration to be clinically acceptable, however other authors ${ }^{(9,10)}$ found that 100 um marginal discrepancy is ideal for the longevity and success of a restoration.

The load bearing capacity of a restoration doesn't only depend on the fracture resistance of the material but also on the adequate preparation design that allow for adequate material thickness ${ }^{(11,12)}$.The shape of the preparation may also affect the stress occurring at the ceramic-tooth complex ${ }^{(13)}$. Oyar et al in $2014{ }^{(14)}$ studied the effect of anatomic and non-anatomic preparations on the stress distribution on ceramic crowns; they found that for Empress crowns non anatomic design can be recommended as a favorable preparation design. 
Invitro testing of dental materials is important to determine the mechanical behavior of the restoration, however it was proven that static loading of the material in a universal testing machine until failure doesn't provide adequate information about the long term clinical performance of the restoration ${ }^{(15)}$. Thus it was generally agreed that fatigue resistance is the most representative of the clinical situation ${ }^{(16)}$.

Therefore the purpose of this in vitro study was to evaluate the internal fit, marginal integrity and fatigue resistance of E-max CAD crowns restoring maxillary central incisors with two different preparation designs.

The null hypothesis was that there will be no difference in the internal fit, marginal integrity and fatigue resistance of E-max CAD restorations for both prepared designs (anatomic and non-anatomic).

\section{MATERIALS AND METHODS}

In the present study twenty defect free human maxillary central incisors were selected having the following inclusion criteria to be restored with E-max CAD crowns.

\section{Inclusion criteria:}

a) All teeth were free from caries, restoration or cracks.

b) Teeth were selected having similar dimensions which was checked by digital caliper mesiodistal, bucco-lingual and inciso-gingival.

c) Teeth were not endodontically treated or previously prepared.

Teeth were collected from the oral surgery clinic at the Faculty of Dentistry, Cairo University.

All teeth were randomly distributed then centrally embedded in epoxy resin blocks $1 \mathrm{~mm}$ below cemento-enamel junction using specially constructed paralling device. This helped in easy handling of the specimens.
Teeth samples were randomly divided into two groups according to the preparation design:

Group A (numbered from 1 to 10) in which preparation was done following the principles of preparation for ceramic restoration in which labial surface of the tooth was reduced in two planes, 1.5 $\mathrm{mm}$ labial reduction, $1 \mathrm{~mm}$ palatal axial reduction and 2-mm incisal reduction using diamond tapered stone with rounded end ${ }^{(17,18,19)}, 1.5 \mathrm{~mm}$ lingual reduction was done by football-shaped stone, the convergence angle of the buccolingual axial walls was 20 degrees which was adjusted by the stone taper ${ }^{(20,21)}, 1 \mathrm{~mm}$ shoulder finish line with rounded internal line angle was made $1 \mathrm{~mm}$ above the cemento-enamel junction ${ }^{(17,18)}$ (Fig. 1.A). All preparation dimensions were verified by silicone index, which was made before the preparation. Finishing of the prepared surfaces to a final smooth preparation with rounded line and point angles.

Group B (numbered from 11 to 20) preparation was done similar to group A except for modification in the palatal surface where the palatal axial wall at the cingulum area was removed by a tapered diamond stone. So the difference between group $\mathrm{A}$ and $\mathrm{B}$ was that group $\mathrm{B}$ did not have parallel labiolingual axial walls (Fig. 1.B).

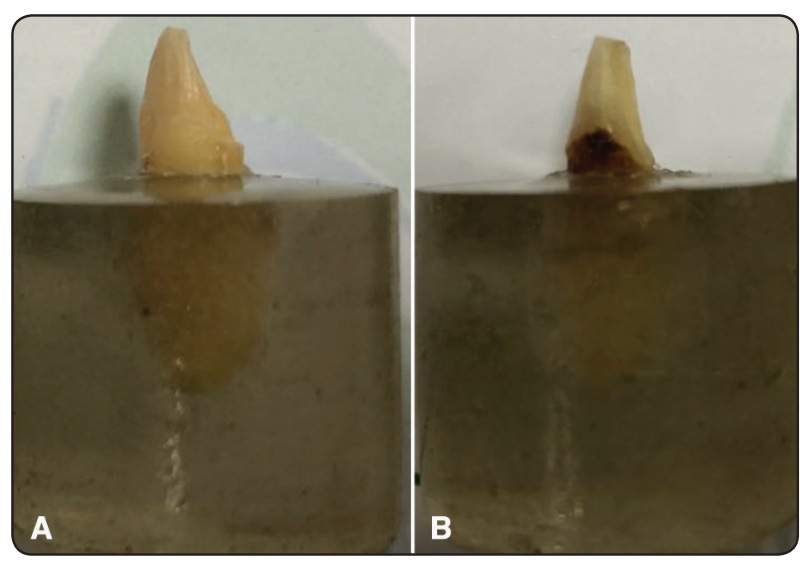

Fig. (1) A: Prepared maxillary anterior teeth with parallel labiolingual wall B: Prepared maxillary anterior teeth with elimination of the palatal wall at cingulum area. 
All preparations were done by one operator for standardization. After first tooth preparations for each group (A, B) another silicon index was made for the prepared tooth in order to standardize the preparation in all teeth in each group.

Scanning was done using powder free Identica hybrid scanner (Medit 02855] 23, Inchon-ro 22-gil, Seongbuk-gu, Seoul, Korea), the standard preparation was also checked during scanning procedure. Designing was made by Exocad software version 2016 (Exocad Gmbh Julius-Reiber-Strabe 37, 64293 Darmstadt, Germany) and die spacer was set to be 60um then the restorations were milled by Roland DWX-510 milling machine (15363 barranca Parkway Irvine, California 92618) from Emax CAD blocks (LT) (Ivoclar Vivadent AG, 9494 Schaan, Liechtenstein). The partially crystalized Emax CAD crowns were then subjected to crystallization according to the manufacturer's instructions in Programmat p310 (Ivoclar Vivadent, Schaan, Liechtenstein).

Try in was made for each restoration over its corresponding prepared tooth.

Duplication of the prepared teeth was done to construct epoxy resin die which were given the same number of the prepared teeth on which the E-max CAD crowns were cemented.

\section{Measurements}

All measurements were done blindly to avoid performance bias.

\section{Internal and marginal integrity}

Internal discrepancy was measured using replica technique. Each restoration was filled with lightbody silicone (Panasil, Kettenbach $\mathrm{GmbH}$ and Co. $\mathrm{KG}$, Eschenburg, Germany) and inserted on the corresponding prepared tooth under a constant load (750 g) for $10 \mathrm{~min}$, by means of a loading device. After the light-body silicone had set, the crown was removed. Since it was not possible to remove the light-body silicone from the interior portions of the crown without distorting it, a heavy-body silicone was used to stabilize the light-body silicone. Using a razor blade $\left(n^{\circ} .15 \mathrm{c}\right)$, the replicas were carefully sectioned into four equal segments buccolingual and mesiodistally.

From the four sections obtained from each replica, two opposite sections were used to measure internal fit, with five points measured on each section (finish line, axial wall, mid-axial, inciso-axial and mid-incisal), yielding 20 internal measurements for each coping. Using USB digital microscope with built in camera (Scope Capture Digital Microscope, Guangdong, China) at $\times 25$ magnification. The light-body silicone thickness for all replicas was measured, representing the distance between the internal surface of the coping and the external surface of the preparation.

A digital image analysis system (Image J 1.43U, National Institute of Health, USA) was used to measure and qualitatively evaluate the gap width. Within the Image J software, all limits, sizes, frames and measured parameters are expressed in pixels. Therefore, system calibration was done to convert the pixels into absolute real world units (i.e. um). Calibration was made by comparing an object of known size (a ruler in this study) with a scale generated by the Image $\mathbf{J}$ software.

\section{Marginal integrity after cementation}

Restorations were then surface treated using Hydrofluoric acid 9\% for 10s (porcelain etchant Bisco; Schaumburg,ILUSA) followed by application of silane coupling agent (Bisco; Schaumburg, IL USA) then cemented on its corresponding epoxy resin dies using dual cured self-adhesive resin cement (Breeze, Pentron Clinical Technologies Wallingford, CT, USA), mixing of the cement was done using automatic mixing tip to ensure the consistency of the cement the cement was applied on the intaglio surface of the restoration and placed 
on the corresponding resin die using finger pressure for initial seating followed by using loading system in order to stabilize the load during cement setting. Application of light was made initially for each surface for 20s then excess cement was removed then light was applied for proper curing, after 24 hours from complete setting of the cement marginal gap was measured. All specimens were preserved in saline solution at room temperature before testing.

Each specimen consists of E-max CAD crown cemented on the corresponding resin die was photographed using measuring Stereomicroscope (Nikon Eclips E600, Tokyo, Japan) connected with an IBM compatible personal computer using a fixed magnification of $45 \mathrm{X}$ (Fig. 2). A digital image analysis system (Image J 1.43U, National Institute of Health, USA) was used to measure and qualitatively evaluate the vertical gap length. Within the Image J software, all limits, sizes, frames and measured parameters are expressed in pixels. Therefore, system calibration was made as done before. Specimens were held in place over their corresponding dies using a specially designed and fabricated holding device. Shots of the margins were taken for each specimen. Then morphometric measurements were done for each shot [3 equidistant landmarks along the cervical circumference for each surface of the specimen (Mesial, labial, distal, and palatal). Measurement at each point was repeated five times. Then the data obtained were collected, tabulated and then subjected to statistical analysis.

\section{Mechanical aging}

Mechanical aging was performed using a programmable logic controlled equipment; the newly developed four stations multimodal ROBOTA chewing simulator integrated with thermo-cyclic protocol operated on servo-motor (Model ACH09075DC-T, AD-TECH TECHNOLOGY CO., LTD., GERMANY)
ROBOTA chewing simulator which has four chambers simulating the vertical and horizontal movements simultaneously in the thermodynamic condition (between $5{ }^{\circ} \mathrm{C} / 55{ }^{\circ} \mathrm{C}$ ). Each of the chambers consists of an upper Jackob's chuck as hardened steel antagonist holder that can be tightened with a screw and a lower plastic sample holder in which the specimen can be embedded (Fig. 2).

The specimens were embedded in Teflon housing in the lower sample holder. A weight of $5 \mathrm{~kg}$, which is comparable to $49 \mathrm{~N}$ of chewing force was exerted with 10,000 cyclic fatigue loading which was done in a study done by Larsson et al in $2007^{(22)}$. (Table 1).

TABLE (1) Thermo-mechanical aging parameters.

\begin{tabular}{|c|c|}
\hline \multicolumn{2}{|c|}{ Parameters for thermo-mechanical aging } \\
\hline $\begin{array}{c}\text { Cold/ hot bath temperature: } 5 \\
{ }^{\circ} \mathrm{C} / 55^{\circ} \mathrm{C}\end{array}$ & Dwell time: $60 \mathrm{~s}$ \\
\hline Vertical movement: $3 \mathrm{~mm}$ & Horizontal movement: $1 \mathrm{~mm}$ \\
\hline Rising speed: $90 \mathrm{~mm} / \mathrm{s}$ & Forward speed: $90 \mathrm{~mm} / \mathrm{s}$ \\
\hline Descending speed: $40 \mathrm{~mm} / \mathrm{s}$ & Backward speed: $40 \mathrm{~mm} / \mathrm{s}$ \\
\hline Cycle frequency $1.6 \mathrm{~Hz}$ & Weight per sample: $5 \mathrm{~kg}$ \\
\hline \multicolumn{2}{|c|}{ Torque; 2.4 N.m } \\
\hline
\end{tabular}

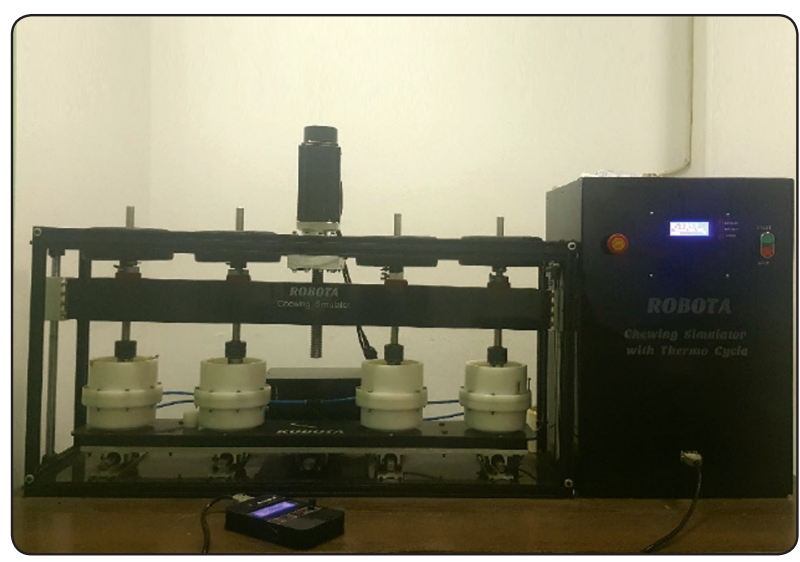

Fig. (2) Robota chewing simulator for thermomechanical aging 


\section{Fatigue resistance}

After $24 \mathrm{hrs}$ of cycling loading the cemented restorations were individually mounted on a computer controlled materials testing machine (Model 3345; Instron Industrial Products, Norwood, MA, USA) with a load cell of $5 \mathrm{kN}$ and data were recorded using computer software (Instron ${ }^{\circledR}$ Bluehill Lite Software). Specimens were secured to the lower fixed compartment of testing machine by tightening screws. Fatigue resistance test was done by compressive mode of load applied at $135^{\circ}$ angle (through fixing the sample in specially designed $45^{\circ}$ angle jig) using a metallic rod with round tip (3.4 mm diameter) attached to the upper movable compartment of testing machine traveling at cross-head speed of $1 \mathrm{~mm} / \mathrm{min}$. with tin foil sheet in-between to achieve homogenous stress distribution and minimization of the transmission of local force peaks. Double blinding was applied in both fatigue resistance measurements and with statician who made the statistical analysis. The load at failure manifested by an audible crack and confirmed by a sharp drop at loaddeflection curve recorded using computer software (Bluehill Lite Software Instron ${ }^{\circledR}$ Instruments). The load required to fracture was recorded in Newton.

\section{RESULTS}

The results were analyzed using Graph Pad Instat (Graph Pad, Inc.) software for windows. A value of $\mathrm{P} \leq 0.05$ was considered statistically significant. Continuous variables were expressed as the mean and standard deviation. After homogeneity of variance and normal distribution of errors had been confirmed, two -way analysis of variance was performed. Student t-test was done for compared pairs. Sample size $(n=20)$ was large enough to detect large effect sizes for main effects and pairwise comparisons, with the satisfactory level of power set at $80 \%$ and a $95 \%$ confidence level.

\section{Internal gap}

Descriptive statistics of internal gap $(\mu \mathrm{m})$ showing mean, standard deviation (SD), minimum, maximum and 95\% confidence intervals (low and high) values for both groups are summarized in (table 2) and graphically drawn in (Fig. 4).

It was found that group $\boldsymbol{A}$ recorded statistically significant higher internal gap mean value $(91.93 \pm 17.41 \mu \mathrm{m})$ than group B $(57.97 \pm 14.08 \mu \mathrm{m})$ as indicated by two-way ANOVA test $(\mathrm{P}=0>0.05)$ as shown in (table 2) and (Fig. 3)

\section{Marginal integrity}

Descriptive statistics of marginal gap $(\mu \mathrm{m})$ showing mean, standard deviation (SD), minimum, maximum and $95 \%$ confidence intervals (low and high) values for both groups before and after cementation are summarized in table (3) and graphically drawn in figure (5).

\section{Comparison between marginal gap before and after cementation for each group}

a) Group A; it was found that cemented subgroup recorded statistically significant $(\mathrm{P}<0.05)$ higher marginal gap mean value $(34.2 \pm 4.84 \mu \mathrm{m})$ than non-cemented subgroup $(25.39 \pm 3.24 \mu \mathrm{m})$ as indicated by paired t-test as shown in table (3) and figure (4).

TABLE (2) Descriptive statistics of internal gap results (Mean values \pm SDs) for both groups

\begin{tabular}{|c|c|c|c|c|c|c|c|}
\hline \multicolumn{2}{|c|}{ Variables } & \multirow{2}{*}{ Mean SD } & \multirow{2}{*}{ Min. } & \multirow{2}{*}{ Max. } & \multicolumn{2}{|c|}{$95 \%$ CI } & \multirow{2}{*}{ Statistics } \\
\cline { 5 - 8 } & & & & Low & High & \multirow{2}{*}{ P value } \\
\hline \multirow{3}{*}{ Group } & Group A & $91.93 \pm 17.41$ & 61.67 & 114.72 & 75.83 & 108.03 & \multirow{2}{*}{$0.0017^{*}$} \\
\cline { 5 - 7 } & Group B & $57.97 \pm 14.08$ & 35.37 & 83.26 & 44.95 & 70.99 & \\
\hline
\end{tabular}

*; significant $(p<0.05)$

ns; non-significant ( $p>0.05$ ) 
TABLE (3) Descriptive statistics of marginal gap results (Mean values SDs) for both groups before and after cementation

\begin{tabular}{|c|c|c|c|c|c|c|c|}
\hline & \multirow{2}{*}{ Variables } & \multirow{2}{*}{ Mean } & \multirow{2}{*}{ $\pm S D$} & \multirow{2}{*}{ Min. } & \multirow{2}{*}{ Max. } & \multicolumn{2}{|c|}{$95 \% C I$} \\
\hline & & & & & & Low & High \\
\hline \multirow{2}{*}{ Group A } & Before cementation & 25.39 & 3.24 & 18.97 & 29.8 & 23.6 & 27.17 \\
\hline & After cementation & 34.2 & 4.84 & 26.48 & 43.15 & 31.54 & 36.86 \\
\hline \multirow{2}{*}{ Group B } & Before cementation & 29.7 & 3.97 & 19.9 & 38.89 & 27.5 & 31.88 \\
\hline & After cementation & 37.15 & 5.34 & 27.43 & 47 & 34.2 & 40.09 \\
\hline
\end{tabular}

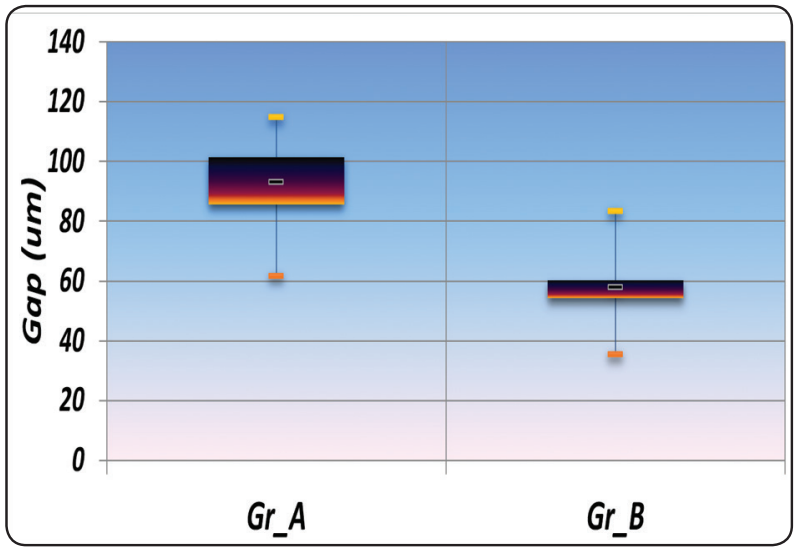

Fig. (3) Box plot comparing total internal gap mean values between both groups.

b) Group B; it was found that cemented subgroup recorded statistically significant $(\mathrm{P}<0.05)$ higher marginal gap mean value $(37.15 \pm 5.34 \mu \mathrm{m})$ than non-cemented subgroup $(29.7 \pm 3.97 \mu \mathrm{m})$ as indicated by paired t-test.

Comparison between marginal gap of groups (A, B) before and after cementation

a) Before cementation; it was found that group $\boldsymbol{B}$ recorded statistically significant $(\mathrm{P}<0.05)$ higher marginal gap mean value $(29.7 \pm 3.97$ $\mu \mathrm{m})$ than group $\boldsymbol{A}(25.39 \pm 3.24 \mu \mathrm{m})$ as indicated by unpaired t-test as shown in table (4).

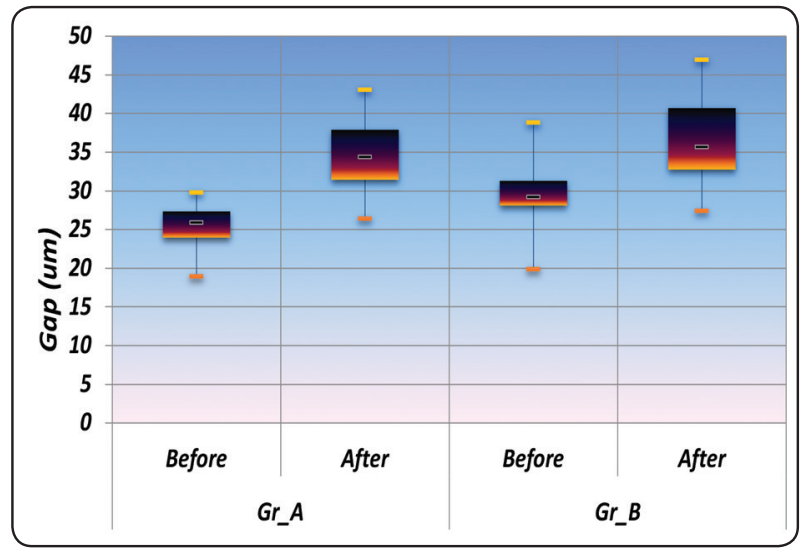

Fig. (4) Box plot of marginal gap mean values for both groups before and after cementation

b) After cementation; it was found that group B recorded statistically non-significant $(\mathrm{P}>0.05)$ higher marginal gap mean value $(37.15 \pm 5.34$ $\mu \mathrm{m})$ than group $\boldsymbol{A}(34.2 \pm 4.84 \mu \mathrm{m})$ as indicated by unpaired t-test as shown in table (4).

Effect of group, regardless to cementation totally there was significant difference between both ceramic groups as indicated by two-way ANOVA test $(\mathrm{p}=0.002<0.05)$ where $($ group $\boldsymbol{B}>$ group $\boldsymbol{A})$

Effect of cementation, irrespective of group type totally cementation affected the marginal gap results significantly as indicated by two-way ANOVA test $(\mathrm{p}=<0.0001<0.05)$ where $($ after cementation $>$ before) 
TABLE (4) Comparison of marginal gap results (Mean values SDs) between both groups before and after cementation

\begin{tabular}{|c|c|c|c|c|}
\hline \multirow{2}{*}{ Variables } & \multicolumn{2}{c|}{ Cementation } & Statistics \\
\cline { 3 - 5 } & Before & After & P value \\
\hline \multirow{3}{*}{ Group } & Group A & $25.39 \pm 3.24$ & $34.2 \pm 4.84$ & $<0.0001^{*}$ \\
\cline { 2 - 5 } & Group B & $29.7 \pm 3.97$ & $37.15 \pm 5.34$ & $0.009 *$ \\
\hline \multirow{2}{*}{ Statistics } & P value & $0.0028^{*}$ & $0.1235 \mathrm{~ns}$ & \\
\hline
\end{tabular}

*; significant $(p<0.05)$

ns; non-significant $(p>0.05)$

\section{Fatigue resistance results}

Descriptive statistics of fatigue resistance test results; mean values, standard deviation $(\mathrm{SD})$ and confidence intervals (95\% CI) (low and high) for both groups after aging are summarized in table (5) and graphically drawn in figure (5).

It was found that Group $\boldsymbol{B}$ recorded higher fatigue resistance mean value $(1130.58 \pm 31.53 \mathrm{~N})$ than Group A value (1114.84+45.04N).

The difference between both groups was statistically non-significant as indicated by t-test $(\mathrm{t}=1.3, \mathrm{p}$ value $=0.588>0.05)$

TABLE (5) Comparison of fatigue resistance results (Mean values \pm SD) between both groups

\begin{tabular}{|c|l|c|c|c|}
\hline \multicolumn{2}{|c|}{} & \multirow{2}{*}{ Variables } & Mean $\pm \mathrm{SD}$ & \multicolumn{2}{c|}{$\begin{array}{c}\text { 95\% Confidence } \\
\text { intervals }\end{array}$} \\
\cline { 4 - 5 } & & Lower & Upper \\
\hline \multirow{2}{*}{$\begin{array}{c}\text { Ceramic } \\
\text { group }\end{array}$} & Group A & $1114.84 \pm 45.04$ & 1069.03 & 1159.19 \\
\cline { 2 - 5 } & Group B & $1130.58 \pm 31.53$ & 1092.01 & 1162.18 \\
\hline \multirow{2}{*}{ t-test } & t-value & \multicolumn{3}{|c|}{1.3} \\
\cline { 2 - 5 } & P value & \multicolumn{3}{|c|}{$0.588 \mathrm{~ns}$} \\
\hline
\end{tabular}

*; significant $(p<0.05)$

ns; non-significant ( $p>0.05)$

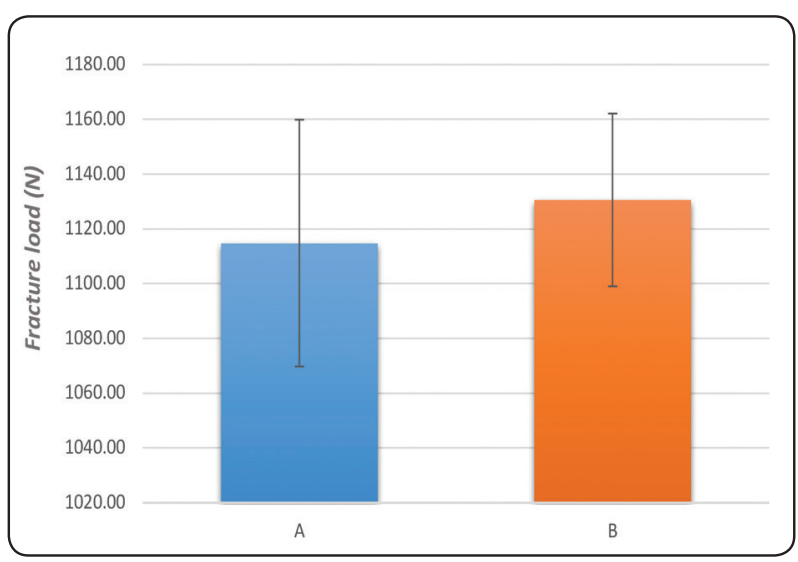

Fig. (5) Column chart comparing mean values between both ceramic groups after thermo-mechanical aging protocol

\section{DISCUSSION}

The purpose of this in-vitro study was to evaluate the internal adaptation, marginal gap before and after cementation and the fatigue resistance after cyclic loading of E-max CAD crowns on two preparation designs of maxillary anterior teeth.

In this study defect free extracted maxillary central incisors were collected according to previous inclusion criteria. Two different preparation designs of ceramic E-max CAD crowns were conducted. Teeth were prepared according to clinically established preparation criteria for all ceramic restoration. The preparations were done by the same operator for standardization.

Two indexes were made first one to evaluate the amount of reduction on first prepared tooth and the second index for duplication of same preparation for remaining teeth.

Although various machinable materials are available for fabricating all ceramic restorations using CAD/CAM systems, E-max CAD blocks were chosen because they have the advantages of long term clinical acceptability, high mechanical as well as esthetic properties and its bondability.

Internal fit, marginal adaptation and fatigue resistance after cyclic fatigue loading were chosen in this study as they are among the critical factors that 
determine the success and longevity of a restoration. There are different methods to evaluate the internal and marginal adaptation, in this study the replica technique was used as it have been widely used as a non-destructive method which requires seating of the restoration on the prepare tooth using the impression material instead of the cement and then after setting the impression is carefully separated and the cement layer analogue is measured ${ }^{(23)}$. Fatigue loading was performed for all the specimens to mimic the oral conditions as it was proved to have an effect on retention and fracture strength of dental ceramics. As ceramics are brittle materials having pre-existing flaws and cracks which with repeated loading fuse to a growing fissure that weakens the restoration ${ }^{(24,25)}$. Therefore, it was more relevant to test the specimens under fatigue load instead of monostatic single loading. Cementation of the restoration and fatigue loading were done on epoxy resin die as its modulus of elasticity is similar to that of the dentine.

10,000 cycles were carried out under $49 \mathrm{~N}$ load at a frequency of $1 \mathrm{~Hz}$ which was done in a similar study carried out by Larsson et al in $2007^{(26)}$.

Studies have shown that thermocycling is important to simulate clinical environment in most of the studies the temperature falls in the range of $5-55^{\circ} \mathrm{C}$ which the ISO standard indicated as an appropriate temperature extremes ${ }^{(27)}$.

The most common type of ceramic restoration failure is due to its fracture under fatigue which is mostly related to the resistance form that is why resistance considered more important than retention especially in anterior restorations.

Application of load in the universal testing machine at $135^{\circ}$ angle on the palatal surface to simulate the clinical condition as it was reported by Guzy and Nicholls ${ }^{(28)}$ that loading angle of $135^{\circ}$ simulates the contact angle observed clinically between the maxillary and mandibular anterior teeth. Double blinding was applied with all measurements (internal adaptation, marginal gap and fatigue resistance) and with statician to avoid performance bias.

The null hypothesis was partially rejected as there was statistically significant difference in internal and marginal adaptation before cementation between the two different preparation designs for Emax CAD crowns. While it was accepted as non-anatomic group (B) showed higher fatigue resistance as well as marginal gap after cementation than anatomic group (A) but with no significant difference.

The results of the marginal and internal adaptation were in accordance with study done by Seo et al in $2009{ }^{(29)}$ which showed difference in marginal and internal gaps with different preparation designs. Nawafleh et al in $2017^{(30)}$ mentioned that measuring the marginal adaptation of a restoration is affected by many variables including the type of the study weather invivo or invitro, the method used for measuring, the number of measurement taken and whether measurement is taken before or after cementation. It was found that marginal discrepancy is directly affected by cementation which was in agreement with many studies showing higher marginal gap after cementation of the restoration ${ }^{31-}$ 35) this was in accordance with the results obtained in this study which showed higher marginal gap after cementation in both groups as well as between samples of the same group.

As group A showed significant less internal adaptation which allowed for more cement thickness which may affect its fatigue resistance compared to group B. This was in accordance with other studies which showed that the internal and marginal adaptation of a restoration affect its fracture resistance where the increase in the marginal and internal gap adversely affect its fracture resistance ${ }^{(36,37)}$.

On the other hand the performance of ceramic crown is dependent on many factors one of which is the configuration of the preparation ${ }^{(14)}$ in this study the difference in preparation designs affect the fatigue resistance of the restoration with the preparation with the palatal wall eliminated 
offers higher fatigue resistance $(1130.58 \pm 31.53 \mathrm{~N})$ than the preparation with parallel labiolingual wall $(1130.58 \pm 31.53 \mathrm{~N})$ but with no significant difference. There were no studies found that evaluated the fracture resistance of the two preparation design. However Bintivanou et al in $2017^{\left({ }^{(38)}\right.}$ showed difference in retention and resistance form of the two preparation designs for maxillary anterior teeth. Further invitro studies evaluating other parameter as construction techniques and different types of ceramics as well as cement types in addition to the long term clinical studies that are highly recommended.

\section{CONCLUSION}

Within the limitation of this study the following could be drawn:

1. Different preparation designs (anatomical and non-anatomical) for anterior maxillary teeth affect the marginal adaptation of the restoration which was statistically significant only before cementation.

2. The internal adaptation of the non-anatomic preparation design considered higher than anatomic preparation one but both were within clinical acceptance.

3. Preparation with elimination of the palatal wall (non-anatomic design) showed insignificant higher fatigue resistance after thermocyclic loading than preparation with parallel labiolingual walls (anatomic design).

\section{REFERENCES}

1. Shillingburg HT, Jacobi R, Brackett SE. Fundamentals of tooth preparations for cast metal and porcelain restorations. Hanover Park: Quintessence Publishing; 1987 .p. 13, 25, 27, 29, 267.

2. Gilboe DB, Teteruck WR. Fundamentals of extracoronal tooth preparation. Part I. Retention and resistance form. J Prosthet Dent 1971;32:651-6.

3. Maglad AS, Wassell RW, Barclay SC, Walls AWG. Risk management in clinical practice. Part 3. Crowns and bridges. Br Dent J 2010;209:115-22.
4. Jorgensen KD. The relationship between retention and convergence angle in cemented veneer crowns. Acta Odontol Scand 1955;13:35-40.

5. Goodacre CJ, Campagni WV, Aquilino SA. Tooth preparations for complete crowns: an art form based on scientific principles. J Prosthet Dent 2001;85:363-76.

6. Kokubo Y, Ohkubo C, Tsumita M, Miyashita A, Vult von Steyern P, Fukushima S. Clinical marginal and internal gaps of Procera AllCeram crowns. Journal of Oral Rehabilitation 2005;32:526-30.

7. Beuer F, Aggstaller H, Edelhoff D, Gernet W, Sorensen J. Marginal and internal fits of fixed dental prostheses zirconia retainers. Dental Materials 2008.

8. McLean JW, von Fraunhofer JA. The estimation of cement film thickness by an in vivo technique. Br Dent $\mathrm{J}$ 1971;131:107-11.

9. Fransson B, Oilo G, Gjeitanger R. The fit of metal-ceramic crowns, a clinical study. Dent Mater 1985;1:197-9.

10. Kashani HG, Khera SC, Gulker IA. The effects of bevel angulation on marginal integrity. J Am Dent Assoc $1981 ; 103: 882-5$

11. Reich S, Petschelt A, Lohbauer U. The effect of finish line preparation and layer thickness on the failure load and fractography of $\mathrm{ZrO} 2$ copings. J Prosthet Dent 2008;99:369-76.

12. Thompson VP, Rekow DE. Dental ceramics and the molar crown testing ground. J Appl Oral Sci 2004;12:26-36.

13. Shahrbaf S, vanNoort R, Mirzakouchaki B, Ghassemieh E. Effect of the crown design and interface lute parameters on the stress-state of a machined crown-tooth system: a finite element analysis. Dent Mater 2013;29:e123-31

14. Oyar P, Ulusoy M and Eskitascioglu G. Finite element analysis of stress distribution in ceramic crowns fabricated with different tooth preparation designs. J Prosthet Dent 2014; 112:871-877.

15. Kelly JR: Clinically relevant approach to failure testing of all-ceramic restorations. J Prosthet Dent 1999;81:652-661 .

16. Nawafleh N, Hatamleh M, Elshiyab S and Mack F: Lithium Disilicate Restorations Fatigue Testing Parameters: A Systematic Review. Journal of Prosthodontics 2016; 25:116-126.

17. Wiskott HWA. Fixed prosthodontics. Principles and clinics. Hanover Park: Quintessence Publishing; 2011. p. 691-719. 
18. Martignoni M, Schönenberger A. Precision fixed prosthodontics: clinical and laboratory aspects. Hanover Park: Quintessence Publishing; 1990. p. 227-62.

19. Lee MM, Rasimick BJ, Turner AM, Shah RP, Musikant BL, Deutch AS. Morphological measurements of anatomic landmarks in pulp chambers of human anterior teeth. $\mathrm{J}$ Endod 2007;33:129-31.

20. Goodacre CJ, Campagni WV, Aquilino SA. Tooth preparations for complete crowns: an art form based on scientific principles. J Prosthet Dent 2001;85:363-76.

21. Goodacre CJ. Designing tooth preparations for optimal success. Dent Clin North Am 2004;48:359-85.

22. Larrson C., Holm L., Lovgren N., Kokubo Y. and Vult Von Steyern P.: Fracture strength of four-unit Y-TZP FPD cores designed with varying connector diameter. An in-vitro study. Journal of Oral Rehabilitation 2007; 34: 702-709.

23. Rahme HY, Tehini GE, Adib SM, Ardo AS, Rifai KT. In vitro evaluation of the "replica technique" in the measurement of the fit of Procera crowns. Journal of Contemporary Dental Practice 2008;9(2):25-32.

24. Ohayama T., Yoshinari M. and Oda Y.: Effects of cyclic loading on the strength of all-ceramic materials. Int. J. Prosthodont.1999;12:28-37.

25. Kelly J.R.: Clinically relevant approach to failure testing of all ceramic restorations. J. Prosthet. Dent. 1999;81:652-661.

26. Larrson C., Holm L., Lovgren N., Kokubo Y. and Vult Von Steyern P.: Fracture strength of four-unit Y-TZP FPD cores designed with varying connector diameter. An in-vitro study. Journal of Oral Rehabilitation 2007; 34: 702-709.

27. Nawafleh N, Hatamleh M, Elshiyab S and Mack F: Lithium Disilicate Restorations Fatigue Testing Parameters: A Systematic Review. Journal of Prosthodontics 2016; 25:116-126.

28. Guzy GE, Nichols JI. In vitro comparison of intact endodontically treated teeth with and without endo-post reinforcement. J Prosthet Dent 1979; 42(1):39-44.
29. Seo D, Yi Y and Roh B. The effect of preparation designs on the marginal and internal gaps in $\mathrm{Cerec} 3$ partial ceramic crowns. journal of dentistry 2009;37:374-382.

30. Nawafleh NA, Mack F, Evans J, Mackay J, Hatamleh MM. Accuracy and reliability of methods to measure marginal adaptation of crowns and FDPs: a literature review. J Prosthodont 2013;22:419-28.

31. Wolfart S, Wegner SM, Al-Halabi A, Kern M. Clinical evaluation of marginal fit of a new experimental allceramic system before and after cementation. Int $\mathrm{J}$ Prosthodont 2003;16:587-92.

32. Quintas AF, Oliveria F, Bottino MA. Vertical marginal discrepancy of ceramic copings with different ceramic materials, finish lines and luting agents: an in vitro evaluation. J Prosthet Dent 2004;92:250-7.

33. Stappert CFJ, Dai M, Chitmongkolsuk S. Marginal adaptation of three-unit fixed dentures constructed from pressed ceramic systems. Br Dent J 2004;196:766-70.

34. Suarez MJ, Lozano JF, Salido M. Marginal fit of titanium metal-ceramic crowns. Int J Prosthodont 2005;18:390-1.

35. Okutan M, Heydecke G, Butz F. Fracture load and marginal fit of shrinkage free $\mathrm{ZrSiO} 4$ all-ceramic crowns after chewing simulation. J Oral Rehabil 2006;33:827-32.

36. Tuntiprawon M, Wilson PR. The effect of cement thickness on the fracture strength of all-ceramic crowns. Aust Dent J 1995; 40: 17-21.

37. Yildiz C, Vanlioğlu B, EVREN B, ULUDAMAR A and ÖZKAN Y: Marginal-internal adaptation and fracture resistance of $\mathrm{CAD} / \mathrm{CAM}$ crown restorations. Dent Mater J 2013; 32(1): 42-47.

38. Bintivanou A, Pissiotis A and Michalakis K: In vitro assessment of retention and resistance failure loads of two preparation designs for maxillary anterior teeth. J Prosthet Dent 2017;117:517-523. 